\title{
Patterns and predictors of help-seeking contacts with health services and general practitioner detection of suicidality prior to suicide: a cohort analysis of suicides occurring over a two-year period
}

\author{
Gerard Leavey ${ }^{1 *}$, Michael Rosato ${ }^{1}$, Karen Galway ${ }^{2}$, Lynette Hughes', Sharon Mallon ${ }^{3}$ and Janeet Rondon ${ }^{1}$
}

\begin{abstract}
Background: Contact with primary care and psychiatric services prior to suicide may be considerable, presenting opportunities for intervention. However, there is scant knowledge on the frequency, nature and determinants of contact.

Method: Retrospective cohort study-an analysis of deaths recorded as suicide by the Northern Ireland Coroner's Office linked with data from General Practice patient records over a 2 year period

Results: Eighty-seven per cent of suicides were in contact with General Practice services in the 12 months before suicide. The frequency of contact with services was considerable, particularly among patients with a common mental disorder or substance misuse problems. A diagnosis of psychiatric problems was absent in $40 \%$ of suicides. Excluding suicide attempts, the main predictors of a noted general practitioner concern for patient suicidality are male gender, frequency of consultations, diagnosis of mental illness and substance misuse.
\end{abstract}

Conclusions: Despite widespread and frequent contact, a substantial proportion of suicidal people were undiagnosed and untreated for mental health problems. General Practitioner alertness to suicidality may be too narrowly focused.

Keywords: Suicide predictors, Suicidality, Help-seeking, Health services, General practice

\section{Background}

In Western societies the main factors associated with suicide include mental illness, gender, age, social class, unemployment, poor physical health and social isolation $[1,2]$. These factors are also related to help-seeking for mental health problems. Contact with primary care services prior to suicide is common, providing an opportunity for intervention for people recognised as vulnerable. Luoma et al. [3] indicate contact averages of $77 \%$ (range $=55-80 \%$ ) within 12-months, and $45 \%$ (20-76 \%) within 1-month of death. In England, Pearson

\footnotetext{
* Correspondence: g.leavey@ulster.ac.uk

${ }^{1}$ Bamford Centre for Mental Health \& Wellbeing, Ulster University, Cromore

Road, Coleraine BT52 1SA, Londonderry, Northern Ireland

Full list of author information is available at the end of the article
}

et al. [4] found that $91 \%$ of individuals had consulted their general practitioner (GP) at least once in the year before death, with an average of seven consultations, almost double the general population rate [5]. A recent case-control study of suicides in England over a 10-year period showed that suicide risk is associated with increasing frequency of GP consultations, particularly in the three months prior to suicide, with highest risk among patients who consulted with their GP more than twenty-four times in the final year. While approximately one-third of suicides may be in contact with mental health services during the 12-month period, mental illness was frequently unrecognised by GPs [6]. Less than one third of adults with diagnosable mental disorders seek professional help $[7,8]$. 


\section{Study aims}

To examine predictors of contact with health and social care services in the 12 -month period prior to suicide and GP recognition of suicidality.

\section{Study design}

A retrospective cohort analysis of all deaths recorded as suicide over a 2-year period from 1st March 2007-28th February 2009. The data was obtained from the records of the Coroner Service for Northern Ireland (CSNI) and linked to individual General Practice (GP) patient notes.

\section{Ethical approval}

Permission to access the required data from CSNI and GP records was granted using the 'research exemption' Section 33 of the Data Protection Act. Ethical approval for the study was obtained from The UK Office for Research Ethics Committees Northern Ireland (ORECNI).

\section{Methods}

A retrospective cohort study providing an analysis of deaths recorded as suicide by the Northern Ireland Coroner's Office linked with data from General Practice patient records over a 2 year period.

\section{Data collection}

We gathered data from the CSNI records using a selfdesigned and piloted pro-forma. We then examined linked patient GP records from the General Records Office. Data extracted for each case included the following: demographic characteristics (e.g., age, gender, marital status and family circumstances); diagnosis and history of mental and physical health problems; and details of the suicide event and its circumstances.

Using postcode data each record was assigned to one of an eight-fold classification of settlement type derived by the Northern Ireland Statistics and Research Agency (NISRA, 2006) ranging from urban to rural locales. For analysis this was summarised into four categories: urban (comprising the Belfast Metropolitan and Derry Urban Areas); larger towns; smaller towns; and rural (comprising small villages with populations less than 1,000 and hamlets and open country).

Two indicators reflecting socioeconomic circumstances derived from occupation data from the Coroners records were included: those in non-voluntary employment (yes/ no); and social class (grouped as professional, other classifications derived from stated occupation, and others).

Pre-existing mental health problems (MHP) were summarised into three groups: (i) common mental disorders (CMD) included depression, anxiety, phobias, stress, psychological disorders and Posttraumatic stress disorder (PTSD); (ii) severe mental illness (SMI) comprised schizophrenia, psychosis, bipolar disorder and personality disorders; and (iii) alcohol/drugs problems included those with alcohol and/or drug dependency problems. We used the International Classification of Primary Care (ICPC-2) [9] which permits the classification of the patient's reason for encounter, problems managed and primary or general health care interventions. Finally, from the GP record we derived data on help-seeking behaviour and service over the twelve months before death. Additionally, we noted where individual GPs made reference to an individual's potential suicidality.

\section{Data analysis}

These data were systematically checked and validated and analysed using Stata version 13. We used simple descriptive statistics and chi-square tests for differences between categorical variables and the different aspects of healthseeking behaviour relating to suicide. We quantified service access at one month, three months and twelve months prior to death, using means (and medians as appropriate, determined by the Shapiro-Wilks test) and Standard Deviation. T-test and Anovas were used to examine difference in frequency of contact. We used stepwise logistic regression to examine the relationships between the selected risk factors and the likelihood of access to services: from consultations with a psychiatrist in the twelve months prior to the suicide; and access to general practitioner services at the noted time points.

\section{Results}

Of the 399 eligible cases of suicide recorded by the Coroner's Office, GP records were unobtainable for 38 individuals (9.5\% of all cases). These records were excluded from the analysis of service access, which therefore was carried out with a base population of 361 . We found no significant differences in gender, age, locale, marital status, living alone or employment between available and unavailable GP records.

The crude overall suicide rate for Northern Ireland for the 2-year period was 11.3 per 100,000 population. Highest rates were recorded in larger towns (14.1/ 100,000). Table 1 shows the distribution of suicides, by gender and the main parameters known to influence suicide: $80 \%$ of suicides were by males; age at suicide ranged from 11 to 83 years (mean 39 years and SD = 16.3 ) - with the peak age for males being younger than for females (25-34 against 35-44 respectively); $31 \%$ of the cohort lived alone at the time of the suicide; $59 \%$ were in paid employment (66 \% of males and $31 \%$ of females); and $40 \%$ had recorded a prior suicide attempt (54\% of females and $36 \%$ of males). While $6 \%$ of suicides were to those from a professional social class, and $41 \%$ in a social class definable by occupation - 45 and $24 \%$ to males and females respectively - the majority of suicides (54\%) were to those in a social class comprising a combination of categories (including the retired) derived on a basis other than occupation. 
Table 1 Suicides in NI (2007-2009): by gender and the main parameters known to influence suicide

\begin{tabular}{|c|c|c|c|}
\hline & Males & Females & Persons \\
\hline & $(N=321)$ & $(N=78)$ & $(N=399)$ \\
\hline & $\%(95 \% \mathrm{Cl})$ & $\%(95 \% \mathrm{Cl})$ & $\%(95 \% \mathrm{Cl})$ \\
\hline Proportion & $80.45(76.25,84.07)$ & 19.55 (15.93. 23.75) & \\
\hline Age (mean \& standard deviation) ${ }^{a}$ & $39.16(16.21)$ & $39.18(16.57)$ & $39.16(16.27)$ \\
\hline Age group less than 25 & $20.25(16.19,25.03)$ & $21.79(13.86,32.56)$ & $20.55(16.85,24.82)$ \\
\hline $25-34$ & $24.30(19.90,29.32)$ & $15.38(8.84,25.43)$ & $22.56(18.70,26.94)$ \\
\hline $35-44$ & $19.94(15.90,24.70)$ & $28.21(19.18,39.41)$ & $21.55(17.78,25.88)$ \\
\hline $45-54$ & $18.07(14.21,22.69)$ & $20.51(12.82,31.16)$ & $18.55(15.02,22.68)$ \\
\hline $55-64$ & $9.66(6.86,13.43)$ & $5.13(1.90,13.14)$ & $8.77(6.36,11.99)$ \\
\hline 65 plus & $7.79(5.31,11.29)$ & $8.97(4.27,17.90)$ & $8.02(5.72,11.13)$ \\
\hline Living alone: yes & $33.33(28.36,38.71)$ & $21.79(13.86,32.56)$ & $31.08(26.71,35.81)$ \\
\hline In paid work: yes & $66.04(60.66,71.04)$ & $30.77(21.37,42.09)$ & $59.16(54.23,63.89)$ \\
\hline \multicolumn{4}{|l|}{ Social class: } \\
\hline Professional & $5.68(3.60,8.85)$ & $6.41(2.64,14.75)$ & $5.82(3.89,8.62)$ \\
\hline Intermediate; semi-routine; routine & $44.79(39.40,50.34)$ & $24.36(15.95,35.33)$ & $40.76(36.00,45.70)$ \\
\hline Other (including retired) & $49.53(44.02,55.04)$ & $69.23(57.91,78.63)$ & $53.42(48.46,58.31)$ \\
\hline Locale: Urban & $39.88(34.63,45.36)$ & $39.74(29.32,51.19)$ & $39.85(35.13,44.76)$ \\
\hline Large towns & $32.09(27.18,37.42)$ & $33.33(23.60,44.73)$ & $32.33(27.90,37.10)$ \\
\hline Small towns & $6.54(4.29,17.90)$ & $8.97(4.27,17.90)$ & $7.02(4.88,9.99)$ \\
\hline Rural & $21.50(17.32,26.36)$ & $17.95(10.80,28.32)$ & $20.80(17.08,25.09)$ \\
\hline \multicolumn{4}{|l|}{ Prior mental health diagnosis: } \\
\hline None & $43.86(38.17,49.71)$ & $30.43(20.54,42.54)$ & $41.24(36.20,46.47)$ \\
\hline Common mental disorders & $29.82(24.77,35.43)$ & $44.93(33.40,57.03)$ & $32.77(28.06,35.86)$ \\
\hline Severe mental illness & $10.53(7.44,14.69)$ & $17.39(10.01,28.50)$ & $11.86(8.87,15.69)$ \\
\hline Alcohol/drugs related & $15.79(11.98,20.53)$ & $7.25(2.98,16.58)$ & $14.12(10.86,18.18)$ \\
\hline Previous attempts (one or more): yes & $36.45(31.34,41.89)$ & $53.85(42.53,64.78)$ & $39.85(35.14,44.76)$ \\
\hline
\end{tabular}

${ }^{a}$ Numbers represent mean age and standard deviation

\section{Psychiatric diagnoses}

Overall $41 \%$ had no recorded diagnosis for mental health problems (MHP) prior to the suicide. Common mental disorders were recorded for $33 \%$ of the cohort, $12 \%$ with SMI, and $14 \%$ with drugs and alcohol problems.

\section{Factors associated with a recorded diagnosis of mental illness}

We examined specific predictors of having a GPrecorded mental health diagnosis (Table 2). People older than 35 years were more likely to have recorded a mental health problem, compared to their younger counterparts $(\mathrm{OR}=4.31: 95 \% \mathrm{CI} 2.37,7.85$ and $\mathrm{OR}=5.27: \mathrm{CI}$ 2.40, 11.56 for the two older age groups). People living alone or not in paid work were more likely to have a recorded mental illness. Predictably, a recorded mental health problem was more likely amongst those with a history of suicidal behaviour.

\section{Recorded diagnosis of alcohol/drugs problems}

Female suicides were less likely than males to be thus diagnosed $(p<0.05)$ while older people $(55+$ years $)$ were five times more likely than young people $(p<0.001)$. Similarly, those living alone or not in paid work recorded excess likelihoods $(p<0.001)$.

\section{Recorded diagnosis of severe mental illness}

Middle-aged people (35-54 years) were significantly more likely to be diagnosed with SMI, compared to their younger counterparts $(p<0.05)$. Likewise, those living alone or not in paid work both recorded an excess likelihood of having a SMI diagnosis than their associated peers $(p<0.01)$.

\section{Recorded diagnosis for common mental disorders}

Females, people living alone, older age groups and those not in paid work were more likely than their respective counterparts to be diagnosed with an CMD $(p<0.05)$. 
Table $\mathbf{2}$ association between prior diagnoses of mental health problems and predictors of suicide

\begin{tabular}{|c|c|c|c|c|}
\hline & $\begin{array}{l}\text { Common mental disorders } \\
(N=116)^{\mathrm{a}}\end{array}$ & $\begin{array}{l}\text { Severe mental illness } \\
(N=43)\end{array}$ & $\begin{array}{l}\text { Alcohol/drugs related } \\
(N=50)\end{array}$ & $\begin{array}{l}\text { All mental health diagnoses } \\
(N=209)\end{array}$ \\
\hline & OR $(\& 95 \% \mathrm{Cl})$ & OR $(\& 95 \% \mathrm{Cl})$ & OR $(\& 95 \% \mathrm{Cl})$ & OR $(\& 95 \% \mathrm{Cl})$ \\
\hline Gender: Male & 1.00 & 1.00 & 1.00 & 1.00 \\
\hline Female & $1.31(0.61,2.86)$ & $0.77(0.28,2.17)$ & $0.29(0.09,0.98)^{*}$ & $0.93(0.45,1.92)$ \\
\hline Age: $<35$ & 1.00 & 1.00 & 1.00 & 1.00 \\
\hline $35-54$ & $4.37(2.26,8.43)^{* * *}$ & $2.41(0.93,6.27)$ & $6.07(2.56,14.38)^{* * *}$ & $4.31(2.37,7.85)^{* * *}$ \\
\hline $55+$ & $5.93(2.53,13.92)^{* * *}$ & $4.08(1.30,12.86)^{*}$ & $4.63(1.47,14.59)^{* *}$ & $5.27(2.40,11.56)^{* * *}$ \\
\hline Living alone: No & 1.00 & 1.00 & 1.00 & 1.00 \\
\hline Yes & $1.42(0.75,2.70)$ & $2.77(1.20,6.39)^{*}$ & $2.91(1.35,6.28)^{* *}$ & $1.91(1.08,3.40)^{*}$ \\
\hline In paid work: yes & 1.00 & 1.00 & 1.00 & 1.00 \\
\hline No & $2.61(1.23,5.56)^{*}$ & $5.78(1.93,17.34)^{* *}$ & $4.33(1.63,11.51)^{* *}$ & $3.27(1.64,6.53)^{* *}$ \\
\hline Social class: professional & 1.00 & 1.00 & 1.00 & 1.00 \\
\hline (Semi) routine & $3.04(0.78,11.79)$ & $0.30(0.06,1.48)$ & $4.11(0.46,36.46)$ & $2.04(0.61,6.14)$ \\
\hline Other & $1.58(0.39,6.44)$ & $0.36(0.07,1.83)$ & $1.96(0.21,18.76)$ & $1.16(0.37,3.66)$ \\
\hline Locale: Urban & 1.00 & 1.00 & 1.00 & 1.00 \\
\hline Large towns & $0.45(0.22,0.91)^{*}$ & $0.97(0.37,2.50)$ & $0.99(0.42,2.32)$ & $0.62(0.34,1.16)$ \\
\hline Smaller towns & $0.58(0.19,1.79)$ & $1.25(0.26,6.10)$ & $0.87(0.19,4.03)$ & $0.72(0.26,1.99)$ \\
\hline Rural & $0.89(0.42,1.85)$ & $1.67(0.53,5.22)$ & $1.00(0.35,2.93)$ & $1.00(0.50,1.97)$ \\
\hline Prior attempts: no & 1.00 & 1.00 & 1.00 & 1.00 \\
\hline Yes & $2.21(1.18,4.16)^{*}$ & $1.89(0.78,4.59)$ & $3.18(1.41,7.20)^{* *}$ & $4.48(2.35,8.56)^{* * *}$ \\
\hline \multicolumn{5}{|c|}{$\begin{array}{l}\text { Consultation with psychiatrist in the } \\
\text { twelve months prior to suicide: }\end{array}$} \\
\hline No & 1.00 & 1.00 & 1.00 & 1.00 \\
\hline Yes & $3.56(1.75,4.16)^{*}$ & $10.84(4.22,27.84)^{* * *}$ & $3.51(1.46,7.20)^{* *}$ & $2.33(1.32,4.12)^{* *}$ \\
\hline
\end{tabular}

***: $p=0.000 ;{ }^{* *}: p<0.005 ; *$ : $p<0.05$

ahere $\mathrm{N}$ represents the number of observations included in each of the stratified analyses-the numbers of people diagnosed with CMD, SMI etc. All models fully adjusted

\section{Contact with general practice}

Thirty-nine percent of the cohort had at least one consultation in the 30 days prior to the suicide, of whom $88 \%$ attended for MHP. With regard to urban-rural differences we found none associated with either any type of consultation $\left(X^{2}=0.188, p=0.98\right)$ or MHP only $\left(X^{2}=\right.$ $1.484, p=0.69)$. This pattern is similar for the 90-day time-period in which $57 \%$ attended a consultation, with $87 \%$ of these attending for MHP. Finally, in the 12months prior to suicide $82 \%$ of the cohort consulted a GP, and of these $70 \%$ attended for MHP. While we found no significant urban-rural differences for all consultations $\left(X^{2}=0.58, p=0.9\right)$ there was a significant difference for MHP $\left(X^{2}=8.3761, p=0.039\right)$.

We examined independent predictors (age, gender, living alone, paid employment, locale and social class) for GP consultations related to MHP at 1, 3, and 12 months prior to the suicide (Table 3): age (35-54 years) remained the only significant predictor of GP consultation across the three time-points. People in small towns were significantly less likely to make contact at one year only $(\mathrm{OR}=0.18,95 \% \mathrm{CI} 0.06,0.58)$. When the history of prior suicide attempts was included, age and living in a smaller town remained significant predictors at 1 year.

\section{Frequency of consultation}

The overall mean number of consultations with GP services for any reason in the 12 months prior to the suicide was 6.74 (CI 6.45, 7.05) with males significantly less in contact (Mean $=5.92$, CI 5.61, 6.25) compared to females $($ Mean $=9.71$, CI 8.96, 10.52).

Table 4 shows the mean (or median where relevant) number of consultations for mental health problems for various risk factors associated with suicide. Of these gender, locale and prior suicide attempts recorded significantly different means within their defined categories $(P$ $=0.0106, P=0.0166$ and $P=0.0195$ respectively). Simi larly, of the indicators with indicated non-normal distributions-social class and prior diagnosis-both recorded P-values indicating significantly different numbers of consultations within their categories. 
Table 3 attendance at GP services for mental health problems at one, three and twelve months before the suicide

\begin{tabular}{|c|c|c|c|c|}
\hline & \multicolumn{4}{|c|}{ Attendance at GP services prior to suicide: for mental health problems } \\
\hline & $\begin{array}{l}\text { M1: one month } \\
\text { prior to suicide }\end{array}$ & $\begin{array}{l}\text { M2: within three } \\
\text { months }\end{array}$ & $\begin{array}{l}\text { M3:within one year } \\
\text { prior to suicide }\end{array}$ & $\begin{array}{l}\text { M4:within one year } \\
\text { prior to suicide }\end{array}$ \\
\hline & $(N=132)^{a}$ & $(N=193)$ & $(N=293)$ & $(N=293)$ \\
\hline & OR $(\& 95 \% \mathrm{Cl})$ & OR $(\& 95 \% \mathrm{Cl})$ & OR $(\& 95 \% \mathrm{Cl})$ & OR $(\& 95 \% \mathrm{Cl})$ \\
\hline Gender: Male & 1.00 & 1.00 & 1.00 & 1.00 \\
\hline Female & $1.11(0.24,5.17)$ & $1.13(0.35,3.64)$ & $1.70(0.79,3.66)$ & $1.57(0.67,3.64)$ \\
\hline Age: $<35$ & 1.00 & 1.00 & 1.00 & 1.00 \\
\hline $35-54$ & $47.36\left(3.58,625.8^{* * *}\right.$ & $12.92(3.21,52.04)^{* * *}$ & $4.91(2.49,9.67)^{* * *}$ & $5.37(2.57,11.24)^{* * *}$ \\
\hline $55+$ & $4.15(0.81,21.16)$ & $4.24(1.11,16.13)^{*}$ & $1.76(0.84,3.71)$ & $2.06(0.91,4.65)$ \\
\hline \multicolumn{5}{|l|}{ Living alone: } \\
\hline No & 1.00 & 1.00 & 1.00 & 1.00 \\
\hline Yes & $1.21(0.30,4.89)$ & $2.46(0.73,8.27)$ & $1.20(0.65,2.23)$ & $0.93(0.47,1.82)$ \\
\hline In paid work: no & 1.00 & 1.00 & 1.00 & 1.00 \\
\hline yes & $3.10(0.45,21.11)$ & $2.70(0.66,10.98)$ & $0.61(0.30,1.26)$ & $0.63(0.29,1.34)$ \\
\hline Social class: professional & 1.00 & 1.00 & 1.00 & 1.00 \\
\hline (Semi) routine & $4.84(0.24,97.33)$ & $3.44(0.65,18.16)$ & $1.06(0.32,3.51)$ & $0.88(0.25,3.10)$ \\
\hline Other & $6.86(0.30,159.11)$ & $3.19(0.52,19.39)$ & $1.63(0.46,5.75)$ & $1.41(0.38,5.26)$ \\
\hline \multicolumn{5}{|l|}{ Locale: } \\
\hline Urban & 1.00 & 1.00 & 1.00 & 1.00 \\
\hline Large towns & $1.40(0.29,6.74)$ & $1.47(0.45,4.81)$ & $0.86(0.44,1.67)$ & $0.80(0.39,1.66)$ \\
\hline Smaller towns & $1.11(0.16,7.89)$ & $0.70(0.15,3.26)$ & $0.23(0.08,0.66)^{*}$ & $0.18(0.06,0.58)^{* *}$ \\
\hline Rural & $1.13(0.19,4.95)$ & $0.87(0.25,3.01)$ & $0.84(0.39,1.79)$ & $0.99(0.44,2.22)$ \\
\hline Prior attempts: no & & & & 1.00 \\
\hline Yes & & & & $6.76(3.45,13.25)^{* * *}$ \\
\hline
\end{tabular}

\section{GP concern for patient suicidality}

We examined the GP records for any indication that the GP was concerned about a patient's possible suicidality. Table 5 shows the results of a series of logistic regression models to examine for predictors of GP concern of suicidality, excluding those patients who had recorded a prior suicide attempt. In the univariate analyses those most likely to raise GP concern included: patients aged 35-54 years $(\mathrm{OR}=3.31$ : 95\%CI 1.61, 6.79); patients with a prior diagnosed mental illness-especially alcohol/drugs problems and serious mental illness $(\mathrm{OR}=10.15$ : 3.45 , 29.88 and $\mathrm{OR}=11.08: \quad 3.39,36.20$ respectively); and males, approximately twice as likely as females. In the main models (M1 to M4) recording incremental adjustment for socio-demographic and clinical factors, frequency of consultations remains a dominant predictor of GP concern for suicidality $(\mathrm{OR}=1.18: 1.07,1.31)$ in all the models. Similarly, GPs were about five times less likely to document concern for female suicidality (when compared to males) $(\mathrm{OR}=0.18,0.04,0.81)$. Finally, a prior $\mathrm{MH}$ diagnosis remains highly predictive in all models.

\section{Contact with other services}

While $33 \%$ of the cohort were in contact with nursing services, only $7 \%$ of these related to MHP; $17 \%$ had contact with social workers, of which $92 \%$ were mental health-related; and $39 \%$ had contact with Accident and Emergency services, of whom 58 \% had recorded a mental health problem. Just over a third had seen a psychiatrist in the 12 months prior to suicide; and $28 \%$ had been in contact with community mental health services in the prior 12 months. We found no differences across type of services for urban-rural locales. Only $2 \%$ of the cohort were recorded as having received counselling services.

\section{Discussion}

Consistent with other evidence, we found that a majority of people who die by suicide have been in contact with 
Table 4 frequency of consultations for mental health problems within twelve months before suicide

\begin{tabular}{|c|c|c|}
\hline & \multicolumn{2}{|c|}{$\begin{array}{l}\text { Mean or median number of GP } \\
\text { consultations relating to mental health } \\
\text { problems-results included for those } \\
\text { with one or more consultation }\end{array}$} \\
\hline & $\begin{array}{l}\text { Mean consultations } \\
\text { (\& standard Deviation) }\end{array}$ & F; $P$-value \\
\hline Consultations & $6.45(6.88)$ & \\
\hline Gender ${ }^{\mathrm{a}}$ : male & $5.75(6.05)$ & \multirow{2}{*}{$\begin{array}{l}F=6.66 \\
P=0.0106\end{array}$} \\
\hline Female & $8.68(8.76)$ & \\
\hline Age $^{a}:<35$ & $4.97(4.74)$ & \multirow{3}{*}{$\begin{array}{l}F=0.28 \\
P=0.7587\end{array}$} \\
\hline $35-54$ & $7.06(8.12)$ & \\
\hline $55+$ & $7.33(5.60)$ & \\
\hline Living alone ${ }^{a}$ : no & $5.94(6.00)$ & \multirow{2}{*}{$\begin{array}{l}F=0.67 \\
P=0.4137\end{array}$} \\
\hline Yes & $7.45(8.21)$ & \\
\hline Paid work" : no & $7.06(6.31)$ & \multirow{2}{*}{$\begin{array}{l}F=0.19 \\
P=0.6649\end{array}$} \\
\hline yes & $5.98(7.29)$ & \\
\hline \multicolumn{3}{|l|}{ Social class ${ }^{b}$ : } \\
\hline Professional & $6.50(7.58)$ & Kruskal-Wallis \\
\hline $\begin{array}{l}\text { Intermediate, semi-routine/ } \\
\text { routine }\end{array}$ & $3.00(6.29)$ & chi2 $=11.707$ \\
\hline Other & $4.00(7.06)$ & $P<0.003$ \\
\hline Locale type ${ }^{a}$ : urban & $5.38(5.22)$ & \multirow{3}{*}{$\begin{array}{l}F=2.81 \\
P=0.0166\end{array}$} \\
\hline Larger town & $8.42(9.28)$ & \\
\hline $\begin{array}{l}\text { Small towns \& rural - } \\
\text { combined }\end{array}$ & $5.52(4.70)$ & \\
\hline Prior suicide attempts ${ }^{\mathrm{a}}$ : no & $6.16(7.43)$ & \multirow{2}{*}{$\begin{array}{l}F=3.38 \\
P=0.0195\end{array}$} \\
\hline Yes & $6.64(6.52)$ & \\
\hline Prior diagnosis ${ }^{\mathrm{b}}$ : none & $2(4.69)$ & Kruskal-Wallis \\
\hline Common metal disorders & $4.5(6.71)$ & chi2 $=16.818$ \\
\hline Serious mental illness & $3(7.34)$ & \multirow[t]{2}{*}{$P<0.001$} \\
\hline Alcohol/drugs & $6(8.30)$ & \\
\hline
\end{tabular}

${ }^{a}$ Variable normally distributed in cohort - means (\& Standard Deviation) used to describe number of consultations

${ }^{\mathrm{b}}$ Variable not normally distributed in the cohort - median used to describe the number of consultations

primary care within 12 months prior to death. This study offers an enriched understanding of GP contact in that we were able to ascertain the nature of these consultations and their frequency. The majority of contacts were related to mental health problems, with this increasing over time. The likelihood of contact is increased among women, older people and among patients identified as having substance misuse problems [6] and common mental disorders. It is worth noting that people with Severe Mental Illness were less likely to be seen by GPs at any time over the 12 month period than those with CMD and substance misuse problems. Although overall, while women were significantly more likely to be in contact with primary care for any reason, we found no gender differences specifically in relation to mental health contacts.

Despite the high level of contact for mental health related problems, we found that GP recorded mental health diagnoses (40\%) were similar to that described elsewhere (NCISH, 2014). This may be explained by either GP underestimation of the severity of problems and/or an unwillingness to formally diagnose. While many patients conceal or downplay the severity of symptoms, the detection of suicidal intent remains a major challenge. This is not just a problem within primary care. Thus, while many people had been in contact with a nurse, this predominantly concerned non-mental health problems. When considering the suicidality of patients GPs tended to be strongly influenced by the gender of the patient and previous psychiatric history. While this may appear a legitimate response - acknowledgement of well-known risk factors - it appears to be based on a degree of profiling which may be at the expense of patients without these characteristics.

Worryingly, only $2 \%$ of patients appeared to be in receipt of counseling services. However, it is likely that other people will have sought such services privately or were referred to third sector agencies. Unfortunately, primary care appears not to have any connection with, or feedback from, these external services.

Recent evidence from various national settings suggests a general trend of increasing rural suicide when compared to urban areas [10-13]. The evidence for differences in urban-rural suicide mortality in Northern Ireland is less clear $[14,15]$. Our analysis of urban-rural locale was based on a graded four-fold classification, allowing for more nuanced urban-rural analysis. We found that the highest suicide rates were recorded for those in larger towns. Explanations for this excess are lacking: there is no evidence that socio-economic problems are worse in towns relative to other locales or that service provision is poorer [16]. In addition to the higher suicide rates within towns,we found a significantly higher level of primary care contact among all suicides, particularly among women. It may be that towns have a relatively underdeveloped mental health provision within the voluntary and private sectors, compared to cities, placing a greater demand on primary care services.

\section{Conclusions}

These findings suggest that too high a proportion of suicidal people remain undiagnosed and untreated for mental health problems. Every contact with professional health services represents a potential opportunity for recognising suicidality among patients. A minority of people who take their own lives appear not to make contact with medical professionals of any type and apparently complete the suicide at the first attempt [17]. 
Table 5 Factors related to general practitioner vigilance to suicidality ${ }^{a}$

\begin{tabular}{|c|c|c|c|c|c|}
\hline & Univariate analysis $^{\mathrm{b}}$ & $\begin{array}{l}\text { M1: adjusted for } \\
\text { consultations, } \\
\text { age \& gender }\end{array}$ & M2: M1 + diagnosis & $\begin{array}{l}\text { M3: M2 + socio- } \\
\text { demographic }\end{array}$ & M4: M3 + locale \\
\hline GPconsultations: number ${ }^{c}$ & $1.18(1.10,1.27)^{* * *}$ & $1.24(1.12,1.36)^{* * *}$ & $1.20(1.08,1.33)^{* * *}$ & $1.20(1.08,1.33)^{* *}$ & $1.18(1.07,1.31)^{* *}$ \\
\hline Age: $35-54(r e f=<35)$ & $3.31(1.61,6.79)^{* * *}$ & $2.09(0.94,4.62)$ & $1.25(0.51,3.03)$ & $1.20(0.48,2.99)$ & $1.20(0.47,3.11)$ \\
\hline $55+$ & $2.11(0.86,5.20)$ & $0.67(0.21,2.18)$ & $0.50(0.14,1.79)$ & $0.49(0.13,1.88)$ & $0.52(0.13,2.15)$ \\
\hline Gender: female (ref = male) & $0.50(0.18,1.38)$ & $0.18(0.04,0.72)^{*}$ & $0.19(0.05,0.79)^{*}$ & $0.21(0.05,0.89)^{*}$ & $0.18(0.04,0.81)^{*}$ \\
\hline \multicolumn{6}{|l|}{ MH problems: (ref = none) } \\
\hline Common MH problems & $5.24(2.36,11.62)^{* * *}$ & & $2.75(1.06,7.14)^{*}$ & $2.86\left(1.09,7.53^{)^{*}}\right.$ & $3.47(1.25,9.66)^{*}$ \\
\hline Serious mental illness & $11.08(3.39,36.20)^{* * *}$ & & $7.76(2.03,29.67)^{* *}$ & $8.61(2.13,34.85)^{* *}$ & $8.08(1.94,33.71)^{* *}$ \\
\hline Drugs/alcohol problems & $10.15(3.45,29.88)^{* * *}$ & & $4.34(1.18,16.0)^{*}$ & $4.74(1.23,18.17)^{*}$ & $4.28(1.13,16.25)^{*}$ \\
\hline Lives alone: yes (ref = no) & $1.35(0.67,2.68)$ & & & $0.85(0.34,2.12)$ & $0.74(0.28,1.95)$ \\
\hline In paid work: no (ref = yes) & $0.87(0.45,1.65)$ & & & $0.79(0.34,1.87)$ & $0.90(0.37,2.22)$ \\
\hline $\begin{array}{l}\text { Locale: large towns } \\
\text { (ref = urban) }\end{array}$ & $1.99(0.94,4.22)$ & & & & $2.35(0.93,5.60)$ \\
\hline Small towns ${ }^{d}$ & na & & & & na \\
\hline Rural areas & $1.65(0.74,3.65)$ & & & & $1.65(0.60,4.56)$ \\
\hline
\end{tabular}

${ }^{* * *}=p<0.001 ;{ }^{* *}=S<0.005 ;{ }^{*}=0.05$

a Analysis includes only those who have no history of prior attempts

${ }^{b}$ Data represents Odds Ratios (ORs) indicating the likelihood of the patient having discussed suicide with their GP

c Number of consultations entered into the model as continuous-ORs represent the increase in likelihood of engagement per additional consultation

' The category 'small towns' predicts the outcome perfectly-they are therefore dropped from the analysis

Nevertheless these findings suggest that contact with services among a majority of suicides may be considerable and, consonant with other research, we suggest that frequent attendance can be a marker for risk, as can receiving different kinds of medication for mental health problems [6]. However, suicide remains a rare event and screening for suicide among high-risk patients may not be a cost-effective suicide prevention strategy $[18,19]$.

\section{Limitations}

A limitation of studies such as this is that we lack an appropriate comparison group. Although we cannot say whether this population differed substantially in their contact with services than the general population, they appear to have visited their GP much more often [5]. Although we were unable to obtain GP records for $9.5 \%$ of the suicides, these are unlikely to have significantly affected the overall findings. As noted previously, rural environments vary considerably ensuring that international comparisons are problematic. In any case, we are unable to address the 'life-history' transition of people from one locale to another. The lack of standardisation in GP terminology for drug and alcohol problems presents a challenge to studies of this kind and, therefore, we were unable to distinguish any primary concern of the GP, if one existed. Moreover, the diagnostic data is derived from the International Classification of Primary Care (ICPC-2, which is limited to a primary diagnosis only. Co-morbidity may be an additional risk factor in determining help seeking-perhaps more so for those with undetected (and therefore, undiagnosed drug or alcohol problems).

Lastly, while our study benefits from the additional more finely grained data from GP records, rather than those from coroner's records only, missing data on contact with other services remains a possibility.

\section{Ethics}

This study was granted a favourable opinion by the Office for Research Ethnics Northern Ireland (ORECNI), a branch of the National Research Ethics Service in the United Kingdom (REC reference: 10/NIR03/65).

\section{Consent to publish}

Permission to access the required data from Coroners Service Northern Ireland and General Practice records was granted under Section 33 of the Data Protection Act.

\section{Availability of data and materials}

The data can be made available by agreement with the principal investigator.

\section{Abbreviations}

CMD: common mental disorders; CSNI: Coroner Service for Northern Ireland: GP: general practitioner; ICPC-2: International Classification of Primary Case (ICPC-2): MHP: mental health problems; NISRA: Northern Ireland Statistics and Research Agency; PTSD: posttraumatic stress disorder; UK-ORECNI: United Kingdom Office of research ethic committees (Northern Ireland).

Competing interest

The authors declare that they have no competing interests. 


\section{Authors' contributions}

The study was designed by GL (Principal Investigator) and KG; MR, GL and KG did the data analysis. LH, SM, KG and JR collected the data. All authors contributed to the writing of the paper and have read and approved the final version of the manuscript.

\section{Acknowledgements}

The R\&D Division of the Public Health Agency Northern Ireland funded this study (Grant COM/4032/08).

\section{Funding}

Research \& Development Division of the Northern Ireland Public Health Agency. Grant number COM/4032/08.

\section{Author details}

${ }^{1}$ Bamford Centre for Mental Health \& Wellbeing, Ulster University, Cromore Road, Coleraine BT52 1SA, Londonderry, Northern Ireland. ${ }^{2}$ School of Nursing and Midwifery, Queen's University Belfast, Medical Biology Building, 97 Lisburn Road, Belfast BT 9 7BL, Northern Ireland. ${ }^{3}$ Faculty of Health and Social Care, Horlock Building, Open University, Milton Keynes MK7 6AA, Northern Ireland.

\section{Received: 23 October 2015 Accepted: 21 April 2016}

Published online: 30 April 2016

\section{References}

1. Pitman A, Krysinska K, Osborn D, King M. Suicide in young men. Lancet. 2012;379(9834):2383-92.

2. Bertolote JM, Fleischmann A. Suicide and psychiatric diagnosis: a worldwide perspective. World Psychiatry. 2002;1:181-5.

3. Luoma JB, Martin CE, Pearson JL. Contact with mental health and primary care providers before suicide: a review of the evidence. Am J Psychiatry. 2002:159:909-16.

4. Pearson A, Saini P, Da Cruz D, Miles C, While D, Swinson N, et al. Primary care contact prior to suicide in individuals with mental illness. $\mathrm{Br} J \mathrm{Gen}$ Pract. 2009;59:825-32.

5. Galway KJ, Murphy AW, O' Reilly D, O' Dowd T, O' Neill C, Shryane E, Steele K, Bury G, Gilliland A, Kelly A. Perceived and reported access to the general practitioner: an international comparison of universal access and mixed private/public systems. Ir Med J. 2007:100(6):494-7.

6. NCISH. National confidential inquiry into suicide and homicide by people with mental illness: suicide in primary care in England: 2002-2011. Manchester: University of Manchester; 2014.

7. Oliver MI, Pearson N, Coe N, Gunnell D. Help-seeking behaviour in men and women with common mental health problems: cross-sectional study. $\mathrm{Br} J$ Psychiatry. 2005:186:297-301.

8. Andrews G, Issakidis C, Carter G. Shortfall in mental health service utilisation. Br J Psychiatry. 2001;179:417-25.

9. WHO. ICPC-2: international classification of primary care. Oxford: Oxford University Press; 1998.

10. Hirsch JK. A review of the literature on rural suicide: risk and protective factors, incidence, and prevention. Crisis. 2007;27(4):189-99.

11. Page A, Morrell S, Taylor R, Dudley M, Carter G. Further increases in rural suicide in young Australian adults: secular trends, 1979-2003. Soc Sci Med. 2007;65(3):442-53.

12. Alston M. Rural male suicide in Australia. Soc Sci Med. 2012;74:515-22.

13. Office for National Statistics. Differences in mortality between rural and urban areas in England and Wales, 2002-04. In: Health statistics quaterly. 2008. p. 39.

14. O' Reilly D, Rosato M, Connolly S. Urban and rural variations in morbidity and mortality in Northern Ireland. BMC Public Health. 2007;7:1-6.

15. O'Reilly D, Rosato M, Connolly S, Cardwell C. Area factors and suicide: 5-year follow-up of the Northern Ireland population. Br J Psychiatry. 2008;192:106-11.

16. Northern Ireland Statistical Agency (NISRA). Northern Ireland deprivation measure. In: Belfast department of finance and personnel. 2010

17. Mallon S, Rosato M, Galway KJ, Hughes L, Rondon J, McConkey S, Leavey G. Patterns of presentation for attempted suicide: analysis of a cohort of individuals who subsequently died by suicide. Suicide Life Threat Behav. 2014:45(3):335-44

18. O'Connor E, Gaynes BN, Burda BU, Soh C, Whitlock E. Screening for and Treatment of Suicide Risk Relevant to Primary Care: A Systematic Review for the U.S. Preventive Services Task Force. Ann Intern Med. 2013;158:741-54.

19. Mann J, Apter A, Bertolote J, et al. Suicide Prevention Strategies: A Systematic Review. JAMA. 2005:294(16):2064-74.

\section{Submit your next manuscript to BioMed Central and we will help you at every step:}

- We accept pre-submission inquiries

- Our selector tool helps you to find the most relevant journal

- We provide round the clock customer support

- Convenient online submission

- Thorough peer review

- Inclusion in PubMed and all major indexing services

- Maximum visibility for your research

Submit your manuscript at www.biomedcentral.com/submit 